\title{
PRODUÇÃO, COMERCIALIZAÇÃO E DISTRIBUIÇÃO DE SEMENTES CRIOULAS NO MUNICÍPIO DE CANGUÇU/RS: 0 CASO DOS PRODUTORES FAMILIARES VINCULADOS À UNIÃO DAS ASSOCIAÇÕES COMUNITÁRIAS DO INTERIOR DE CANGUÇU (UNAIC)
}

\author{
Éder Jardel da Silva DUTRA ${ }^{1}$ \\ Queli Rejane da Silva KONZGEN² \\ Jussara MANTELLI
}

\section{Resumo}

O presente artigo objetiva caracterizar a produção, comercialização e distribuição de sementes crioulas no município de Canguçu/RS, salientando o papel desenvolvido pela União das Associações Comunitárias do Interior de Canguçu (UNAIC), ao congregar os produtores e organizar a cadeia produtiva das sementes crioulas. Destacam-se também, ao longo do estudo, as perspectivas e as limitações dos agricultores envolvidos na produção. Para o desenvolvimento da pesquisa foram consideradas as seguintes etapas: a) revisão teórica sobre o tema campesinato, agricultura familiar e sementes crioulas; b) caracterização geral do município de Canguçu; c) histórico da UNAIC, através de dados disponíveis no site da associação e conversas informais com os produtores associados; d) realização de entrevistas com todos os agricultores de sementes crioulas vinculados à associação. Observou-se na pesquisa de campo o papel desenvolvido pela instituição para a propagação das sementes crioulas na região. Esse modelo de produção compreende uma forma secundária de renda para os produtores que buscam resgatar a importância das sementes crioulas e convertem-se, em muitos casos, em seus guardiões, retornando assim ao modelo de agricultura praticada em períodos anteriores ao advento da Revolução Verde.

Palavras-chave: Sementes crioulas. Produtores familiares. Canguçu.

\footnotetext{
${ }^{1}$ Bolsista do Programa Nacional de Pós-Doutorado (PNPD), na Universidade Federal do Rio Grande. ICHI/FURG, Avenida Itália, Km 8, Rio Grande/RS - CEP: 96203-900. E-mail: dutraeder1981@gmail.com

2 Mestranda no Programa de Pós-Graduação em Geografia da Universidade Federal do Rio Grande. Bolsista CAPES. ICHI/FURG, Avenida Itália, Km 8, Rio Grande/RS - CEP: 96203-900. E-mail: kellykonzgen@yahoo.com.br

3 Professora Doutora vinculada à Universidade Federal do Rio Grande. ICHI/FURG, Avenida Itália, Km 8, Rio Grande/RS - CEP: 96203-900. E-mail: jussaramantelli@furg.br
} 


\section{Abstract}

\section{Production, commercialization and distribution of native seeds in the municipality of Canguçu/RS: the case of family producers linked to the Union of the Community Associations from the Interior of Canguçu (UNAIC)}

This article aims to characterize the production, commercialization and distribution of native seeds in the municipality of Canguçu / RS, emphasizing the role played by the Union of the Community Associations from the Interior of Canguçu (UNAIC), by bringing together producers and organizing the production chain of native seeds. The perspectives and limitations of farmers involved in the production are also highlighted throughout the study. For the development of the research the following steps were considered: a) theoretical revision on themes such as peasantry, family agriculture and native seeds; b) general characterization of the municipality of Canguçu; c) UNAIC's history, based on data available on the association's website and informal conversations with the associated producers; d) interviews with all the farmers of native seeds linked to the association. In the field research, it was observed the role developed by the institution for the propagation of native seeds in the region. This production model works as a secondary form of income for the producers who seek to rescue the importance of the native seeds, becoming, in many cases, their guardians, therefore returning to the model of agriculture practiced in periods prior to the advent of the Green Revolution.

Key words: Native seeds. Family farmers. Canguçu.

\section{INTRODUÇÃO}

As sementes crioulas são passadas de geração a geração, selecionadas ao longo de vários períodos, sem passar por modificações genéticas em laboratórios. Constituem-se, portanto, em "sementes da resistência" ao avanço dos processos homogeneizantes no campo, representados em parte pelos pacotes tecnológicos fechados e o domínio das transnacionais sobre a produção mundial de alimentos. São diferentes formas de resistir e possibilitar a busca de uma agricultura autônoma. No estado do Rio Grande do Sul, merece referência a União das Associações Comunitárias do Interior de Canguçu (UNAIC), ao congregar produtores e impulsionar a estruturação da cadeia produtiva das sementes crioulas em âmbito municipal e estadual.

O presente artigo tem como objetivo caracterizar a produção, comercialização e distribuição de sementes crioulas no município de Canguçu/RS, salientando o papel desenvolvido pela UNAIC, ao congregar os produtores e organizar a cadeia produtiva das sementes crioulas, e, ao longo do estudo, buscou-se levantar as perspectivas e as limitações dos agricultores envolvidos nessa produção. A realidade apresentada no município é ímpar, uma vez que, a partir da consolidação da Revolução Verde (compreendida aqui como um processo homogeneizante das características da agricultura brasileira), o agricultor foi forçado a abandonar a tradição no que tange à produção de sementes. Entretanto, essa política poderá ser revertida com as iniciativas dos próprios agricultores de buscar alternativas ao modelo instalado pelas empresas sementeiras. O caso dos produtores de sementes crioulas no município de Canguçu é relevante por apresentar aos agricultores a possibilidade de gerar sementes com qualidade e quantidade que atendam a suas necessidades e às demandas locais. 
O município de Canguçu está localizado na região fisiográfica da Serra do Sudeste, no Escudo Cristalino Sul-riograndense, conforme a figura 1 . O município possui uma área de $3.252 \mathrm{~km}^{2}$, dividida em cinco distritos, incluindo a sede. A área de estudo fica a aproximadamente $274 \mathrm{~km}$ de distância de Porto Alegre, capital do estado do Rio Grande do Sul. Segundo o Instituto Brasileiro de Geografia e Estatística IBGE (2010), o município apresenta um total de 53.259 habitantes, dos quais 33.565 $(63,02 \%)$ são residentes da área rural, e $19.694(36,98 \%)$, da área urbana.

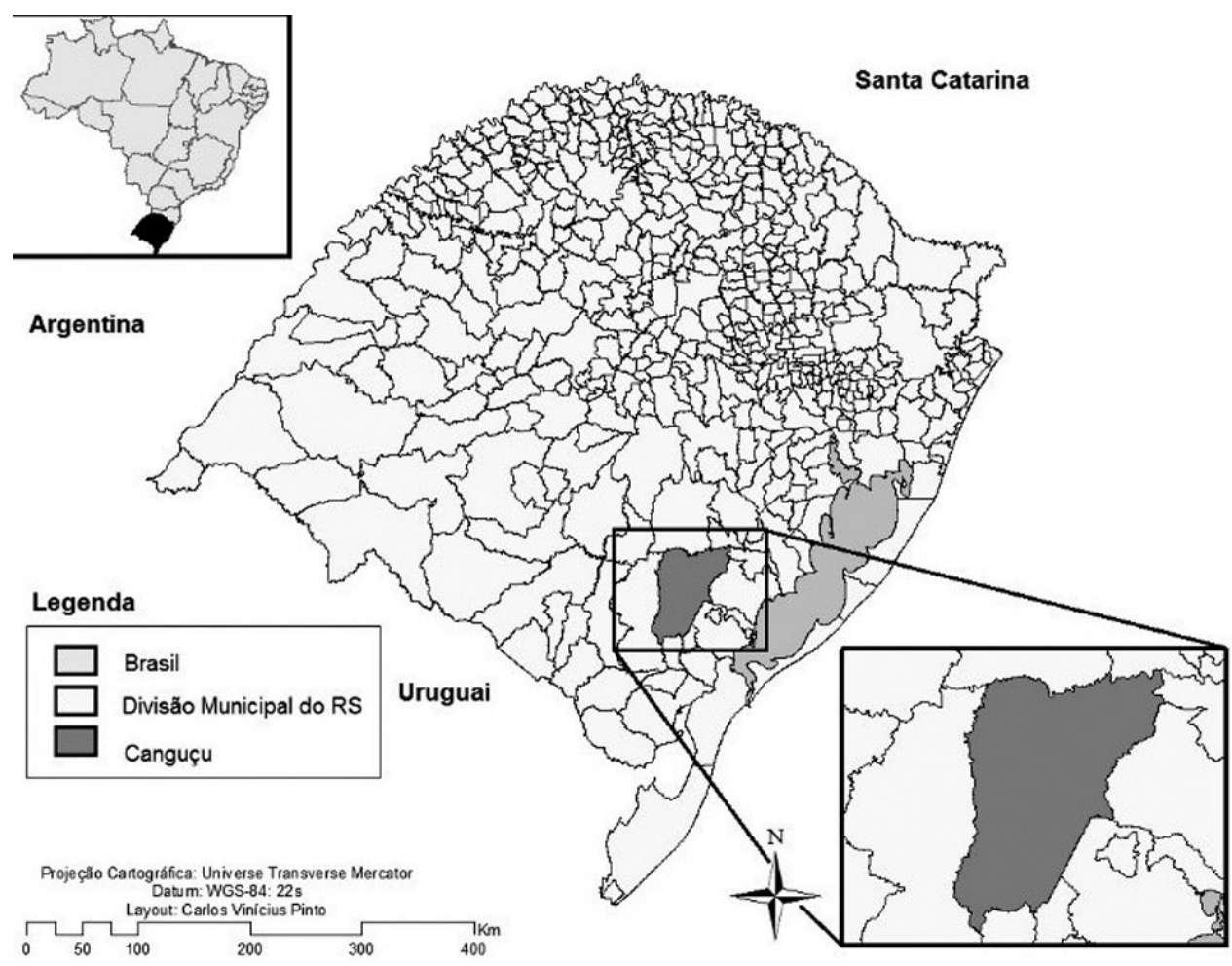

Figura 1 - Mapa de localização do município de Canguçu/RS

Fonte: Elaborado por Carlos Vinícius Pinto, 2015.

O município é conhecido como a Capital Nacional da Agricultura Familiar por apresentar um significativo número de unidades familiares de produção. Segundo os dados do IBGE (2006), Canguçu possui um total de 9.881 estabelecimentos agropecuários, dos quais 1.107 são estabelecimentos não familiares, e o restante (8.774) são estabelecimentos familiares. No município, a retomada da produção de sementes crioulas se dá basicamente a partir dos produtores associados à UNAIC, que atua como mediadora ao congregar os produtores e fomentar a produção, comercialização e distribuição das sementes crioulas. É importante mencionar que os excedentes da produção são comercializados com a UNAIC, como demonstram os resultados das entrevistas. Destaca-se a seguir a metodologia empregada na realização desta pesquisa nas suas distintas etapas, evidenciando a importância das entre- 
vistas para a compreensão da realidade estudada, bem como das visitas às propriedades familiares, para a observação da realidade apresentada "in loco".

\title{
METODOLOGIA
}

Os caminhos teórico-metodológicos seguiram diversas etapas: a) revisão teórica sobre os temas do campesinato, agricultura familiar e sementes crioulas, em especial no Brasil; b) caracterização geral do município de Canguçu através de dados secundários; c) histórico sobre a UNAIC, fundamentado principalmente nas informações disponíveis no site da associação ${ }^{4}$ e em conversas informais com os produtores associados; e d) aplicação de entrevistas compostas por perguntas abertas, feitas aos produtores de sementes crioulas do município de Canguçu e vinculados à UNAIC.

Levando em conta o universo de análise, foi possível entender a realidade que norteia essa atividade. A coleta de dados nas entrevistas e nas observações de campo obedeceram ao ângulo qualitativo da análise. Conforme pontuam Gerhardt e Silveira (2009, p. 32): "A pesquisa qualitativa preocupa-se, portanto, com aspectos da realidade que não podem ser quantificados, centrando-se na compreensão e explicação da dinâmica das relações sociais". Deslauriers e Kérisit (2008, p. 131) destacam que o objeto da pesquisa qualitativa é "[...] a ação interpretada, simultaneamente, pelo pesquisador e pelos sujeitos da pesquisa; de onde a importância da linguagem e das conceituações que devem dar conta do objeto vivido, como do objeto analisado". Com relação à entrevista, Alves Mazzotti e Gewandsznajder (1999, p. 168), destacam que:

\begin{abstract}
Por sua natureza interativa, a entrevista permite tratar de temas complexos que dificilmente poderiam ser investigados adequadamente através de questionários, explorandoos em profundidade. A entrevista pode ser a principal técnica de coleta de dados [...]. As entrevistas qualitativas são muito pouco estruturadas, sem um fraseamento e uma ordem rigidamente estabelecidos para as perguntas, assemelhando-se muito a uma conversa. Tipicamente, o investigador está interessado em compreender o significado atribuído pelos sujeitos a eventos, situações e processos ou personagens que fazem parte de sua vida cotidiana.
\end{abstract}

A entrevista foi a principal técnica de coleta de dados na pesquisa de campo e ocorreu nas unidades familiares de produção no município de Canguçu, a partir da lista de produtores fornecida pela UNAIC. As entrevistas versavam sobre um amplo leque de questões, mas, principalmente, sobre temáticas sintetizadas nos cinco pontos centrais destacados: 1) Qual é a principal fonte de renda da propriedade? 2) O que produz na propriedade em termos de sementes crioulas? Quais variedades produz? 3) Existe viabilidade econômica em produzir sementes crioulas? 4) Qual o destino da produção das sementes crioulas oriundas de sua propriedade? 5) Quais são as perspectivas e os limites da produção de sementes crioulas?

\footnotetext{
4 A UNAIC é uma entidade que congrega diferentes associações comunitárias do interior de Canguçu. Ao longo do texto, quando aparecer o termo cooperativa nas falas dos agricultores, eles estarão falando na UNAIC. Todavia, para poder participar de leilões e chamadas públicas das esferas de governo municipal, estadual e federal foi necessário a criação da Cooperativa União, que passou a operar e intermediar, por exemplo, o Programa de Aquisição de Alimentos (PAA), Programa Nacional de Alimentação Escolar (PNAE), entre outras chamadas públicas.
} 
Como mencionam Richardson et al. (1989, p. 147), a pergunta aberta "[...] deve ser utilizada quando o pesquisador deseja realizar determinado assunto mas não está familiarizado com a população a ser entrevistada e não pode, portanto, antecipar possíveis respostas". Foram entrevistados, nos meses de julho, agosto, setembro, outubro e novembro de 2017 , todos os 17 produtores familiares de sementes crioulas vinculados naquele momento à instituição. Durante o trabalho de campo, foram realizadas outras técnicas de coleta de dados e informações, como observação, levantamento fotográfico e a determinação das coordenadas geográficas das sedes das propriedades, para a posterior elaboração do mapa de localização dos produtores pesquisados (Figura 2). Foi possível verificar, por exemplo, que esses produtores resistiram aos processos hegemônicos de dominação e constituem-se em núcleos de propagação de sementes crioulas.
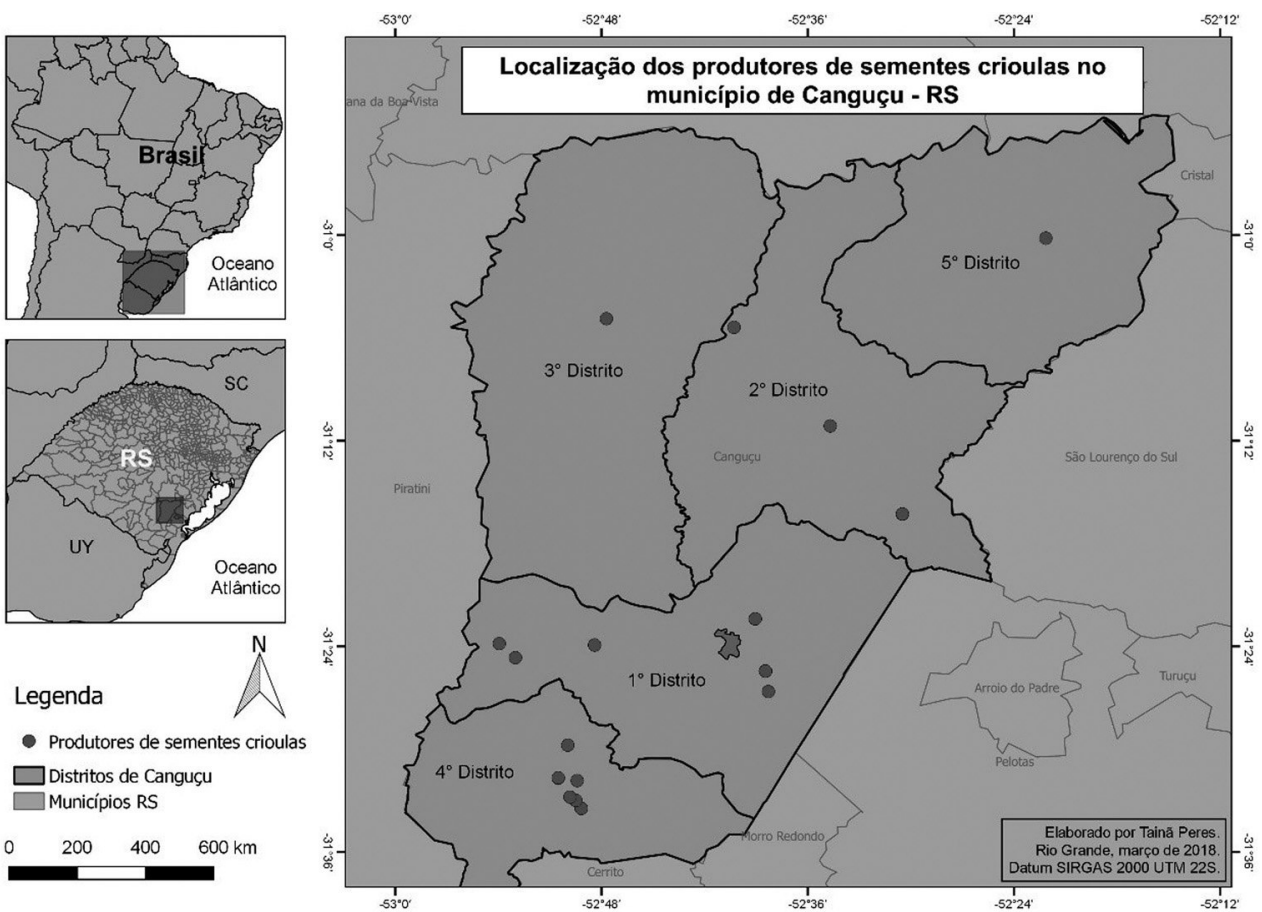

Figura 2 - Mapa de localização das propriedades pesquisadas

Fonte: Elaborado por Tainã Peres, 2018.

Ainda sobre a figura 2, observa-se a localização das 17 propriedades que trabalham com sementes crioulas e que têm a UNAIC como agregadora e estruturadora desse universo produtivo. De modo geral, percebe-se que não existe homogeneidade de distribuição das propriedades estudadas no município. Tem-se a maior concentração no $1^{\circ}$ e $4^{\circ}$ Distritos, com produtores que são referência em qualidade e diversidade da produção. Esses produtores são importantes no trabalho com sementes crioulas, mas principalmente no domínio de tecnologias populares e sua disseminação, como forma de contrapor-se aos pacotes tecnológicos fechados, são, antes de tudo, 
exemplos e formas de resistência às concepções hegemônicas de "estandardização" dos padrões de produção no meio rural.

\section{DE CAMPONÊS A AGRICULTOR FAMILIAR: AS FORMAS DE RESISTÊNCIA}

Segundo Wanderley (1996), o campesinato possui uma cultura própria, como as regras de parentesco, de herança, das formas de vida local, entre outros. Para a mesma autora:

O campesinato corresponde a uma forma social de produção, cujos fundamentos se encontram no caráter familiar, tanto dos objetivos da atividade produtiva - voltados para as necessidades da família - quanto do modo de organização do trabalho, que supõe a cooperação entre os seus membros. A ele corresponde, portanto, uma forma de viver e de trabalhar no campo que, mais do que uma simples forma de produzir, corresponde a um modo de vida e a uma cultura (WANDERLEY, 2014, p. 2).

Oliveira (2001) destaca que os camponeses no Brasil lutam em duas frentes: uma para conseguirem a propriedade da terra, e a outra frente para permanecerem nela como produtores de alimentos. A luta pela terra dos camponeses no país:

[...] é uma luta específica, moderna, característica particular do século XX. Entendo que o século passado foi, por excelência, uma época de formação e consolidação do campesinato brasileiro enquanto classe social. Assim, esses camponeses não são entraves ao desenvolvimento das forças produtivas, impedindo o desenvolvimento do capitalismo no campo; ao contrário, eles praticamente nunca tiveram acesso à terra, sendo pois desterrados, "sem terra", que lutam para conseguir o acesso à terra. É no interior destas contradições que têm surgido os movimentos sociais de luta pela terra, e com ela os conflitos, a violência (OLIVEIRA, 2001, p. 189).

Para Wanderley (2009), a agricultura camponesa tradicional vem a ser uma forma social da agricultura familiar baseada na relação entre propriedade, trabalho e família. A autora complementa afirmando que o agricultor familiar é um novo personagem, diferente do camponês tradicional, que assumiu sua condição de produtor moderno e alvo das políticas públicas para incentivar o desenvolvimento rural (WANDERLEY, 1996).

O conceito de agricultura familiar, segundo Wanderley (2004), disseminou-se no Brasil, principalmente com a implantação do Programa Nacional de Fortalecimento da Agricultura Familiar (PRONAF). Esse programa foi criado em 1996, por meio do Decreto 1.946, de 28 de junho de 1996, com o objetivo de promover o desenvolvimento sustentável da agricultura familiar. De acordo com Wanderley (2004, p. 4344):

Para uns, o conceito agricultura familiar se confunde com a definição operacional adotada pelo Pronaf que propõe uma tipologia de beneficiários em função de sua capacidade de atendimento. Para outros, agricultura familiar corresponde a 
uma certa camada de agricultores, capazes de se adaptar às modernas exigências do mercado em oposição aos demais "pequenos produtores" incapazes de assimilar tais modificações. São os chamados agricultores "consolidados" ou os que têm condições, em curto prazo, de se consolidar. Supõe-se que as políticas públicas devem construir as bases para a formação desse segmento.

Duval, Ferrante e Bergamasco (2015) afirmam que a noção de campesinato foi enfraquecida com o surgimento da agricultura familiar. Mas "a condição camponesa permanece presente no modo de vida de diversas categorias sociais no meio rural e está presente tanto por parte dos autores que usam a terminologia camponês como os que usam agricultura familiar" (DUVAL; FERRANTE; BERGAMASCO, 2015, p. 72). Ainda segundo os autores:

[...] a persistência do campesinato na contemporaneidade está associada ao fato de existirem, atualmente, grupos sociais que vivem no meio rural com características que os aproximam a uma condição camponesa, expressa em modos de vida, reprodução social e cultural, sistemas agropecuários e outras formas de inserção produtiva singulares, situação que reforça as relações entre campo e cidade (DUVAL; FERRENTE; BERGAMASCO, 2015, p. 76).

As ideias de Marx, expostas por Almeida (2007), sobre a utopia da modernidade, na qual ocorreria a separação entre natureza e sociedade, campo e cidade, revelamse inadequadas. Enfatiza-se que "nessa utopia, não haveria lugar para camponeses, porque todos seriam cidadãos urbanos por excelência" (ALMEIDA, 2007, p. 167). Ao contrário disso, o camponês não desapareceu, pois continua resistindo e se reproduzindo no meio rural. A expansão do capitalismo colaborou para a ampliação das atividades familiares, mudando o modo de produção e sua vida social; contudo, a agricultura familiar ainda carrega consigo uma tradição camponesa. Conforme Wanderley (2004), o agricultor familiar é um ator social da agricultura moderna, resultante da própria atuação do Estado. A autora ainda menciona que:

[...] o agricultor familiar não é um personagem passivo sem resistência diante de forças avassaladoras vindas de fora e de cima do seu universo. Pelo contrário, ele constrói sua própria história nesse emaranhado campo de forças que vem a ser a agricultura e o meio rural inseridos em uma sociedade moderna. E o faz recorrendo à sua própria experiência (camponesa) e procurando adaptar-se, como já foi dito, às novas "provocações" e desafios do desenvolvimento rural (WANDERLEY, 2004, p. 58).

O termo agricultura familiar é caracterizado por Neves (2002, p. 137) como "uma categoria de ação política que nomeia um amplo e diferenciado segmento mobilizado à construção de novas posições sociais mediante engajamento político". Seyferth (2011, p. 400-401), aborda que a expressão "agricultura familiar" no Brasil:

[...] põe em evidência o Estado e a política de reconhecimento de direitos territoriais, bandeira de luta dos movimentos pela reforma agrária, pauta das mais antigas e nunca implementada na proporção desejada pelos atores sociais, e pela legitimação da posse da terra por grupos etnicamente definidos. O agricultor familiar (que geralmente tem outras inserções identitárias na vida cotidiana) entra dessa forma na política, reconhecido pelo Estado. A noção de identi- 
dade, coletiva e individual, supõe diferenciação cultural despegada da comunidade fechada, pois os camponeses têm relação com o mundo urbano que vai além da inserção no mercado (esta entidade onipresente na conceituação econômica), e com outros indivíduos e grupos que ocupam o espaço rural. Olhando os discursos "nativos", os próprios camponeses reivindicam um modo de vida diferenciado, articulado a certas percepções de ruralidade.

A Lei no 11.326, de 24 de julho de 2006, que estabelece as diretrizes para a formulação da Política Nacional da Agricultura Familiar e Empreendimentos Familiares Rurais, considera agricultor familiar e empreendedor familiar rural aquele que pratica atividades no meio rural, atendendo aos seguintes requisitos:

I - não detenha, a qualquer título, área maior do que 4 (quatro) módulos fiscais; II - utilize predominantemente mãode-obra da própria família nas atividades econômicas do seu estabelecimento ou empreendimento; III - tenha percentual mínimo da renda familiar originada de atividades econômicas do seu estabelecimento ou empreendimento, na forma definida pelo Poder Executivo; IV - dirija seu estabelecimento ou empreendimento com sua família (BRASIL, 2006).

A citada lei tem um papel importante no reconhecimento e na valorização da agricultura familiar, mas os requisitos definidos são apenas para fins de financiamento. E o conceito de agricultura familiar vai muito além da definição que a norma determina. A agricultura familiar possui raízes no campesinato, como aborda Wanderley (1996), apresentando atualmente ainda um caráter familiar de pequena produção agrícola, uma ligação com a terra, a gestão da propriedade feita pela própria família, enfrentando a falta de acesso à propriedade da terra, entre outros fatores. No caso dos produtores de sementes crioulas, vê-se a racionalidade camponesa presente, marcada na forma de resistência aos processos de domínio das grandes empresas do agronegócio. São realidades pontuadas pelo desejo de autonomia e possibilidades de reprodução social, perpassando pelo que a sociologia rural denomina como campesinato ou suas formas de evolução ao que se convenciona compreender, por força de lei, como agricultura familiar. É dessa realidade que se trata ao destacar a trajetória das sementes crioulas, reafirma-se que é a garantia de uma reprodução social autônoma, identificada com as particularidades locais.

\section{AS SEMENTES CRIOULAS: BREVE CONTEXTUALIZAÇÃO}

Segundo Orlandini (2017), as sementes tradicionais são selecionadas por décadas, passadas de geração a geração, preservadas por famílias de agricultores guardiões ou bancos de sementes que existem no Brasil. Como complementam Amorim et al. (2017, p. 72): "As sementes crioulas são aquelas que não sofreram mudanças genéticas, incluindo a transgenia, e recebem este nome porque historicamente foram manejadas por comunidades camponesas, indígenas e tradicionais". Ao ampliar o leque de análise, Arboldeda (2016, p. 86), com base em Santilli (2009), destaca que: "o manejo dos recursos, no caso das sementes, contribui para a agrobiodiversidade, que, devido às práticas de armazenamento, pode ser conservada nos ambientes naturais (in situ) e nas propriedades rurais pelos agricultores (on farm)". 
No Brasil, a Lei no 10.711/03 dispõe sobre o Sistema Nacional de Sementes e Mudas e descreve em seu Art. $2^{\circ}$, inciso XVI, que as cultivares locais, tradicionais ou crioulas são variedades desenvolvidas, adaptadas ou produzidas por agricultores familiares, assentados da reforma agrária ou indígenas, com características fenotípicas bem determinadas e reconhecidas pelas respectivas comunidades e que, a critério do Ministério da Agricultura Pecuária e Abastecimento (MAPA), considerados também os descritores socioculturais e ambientais, e não se caracterizam como substancialmente semelhantes às cultivares comerciais. Paulino e Gomes (2015, p. 521) mencionam que a referida lei permitiu:

[...] aos agricultores produzirem, trocarem ou venderem sementes e mudas entre si, sem precisarem aderir ao Registro Nacional de Sementes (Renasem) e ao Registro Nacional de Cultivares (RNC), responsáveis pela fiscalização destas trocas mercantis de sementes e mudas. Essa recente brecha aberta na legislação, em 2003, foi um dos fatores que reforçaram as tentativas de legitimação das sementes crioulas por parte dos cientistas e dos agricultores ecológicos.

O panorama dos estados do Sul do Brasil mostra que o resgate e a retomada da produção de sementes crioulas é uma das formas que as famílias encontram para resistir e manter as raízes no campo. Nesse contexto, menciona-se Grígolo (2016, p. 145-146), fundamentado em Vogt e Canci (2007):

Em 1996, no município de Anchieta - Santa Catarina, o Sindicato dos Trabalhadores da Agricultura Familiar de Anchieta (Sintraf/Anchieta) começou, junto com a prefeitura e ONGs, um trabalho de resgate e conservação de variedades locais. [...] Objetivou-se, assim, a autonomia técnica e econômica em relação às agroindústrias. Conferiu-se destaque para o milho em razão de ser muito utilizado pelos agricultores para a criação de animais, sendo portanto central para as famílias agricultoras. A estratégia visava diminuir custos e assegurar a segurança alimentar através do uso da agrobiodiversidade.

Aquini (2015, p. 15-16) destaca sobre os guardiões das sementes crioulas, em especial no Rio Grande do Sul:

[...] há no estado, guardiões de sementes descendentes de escravos remanescentes de quilombos, indígenas e descendentes de outras etnias - entre as quais portugueses, pomeranos, alemães e italianos. [...] em 2008, agricultores da região Centro Serra criaram a Associação dos Guardiões das Sementes Crioulas de Ibarama, com o objetivo de preservar e transmitir os saberes tradicionais locais; buscar conhecimentos sobre práticas agroecológicas e desenvolver o cultivo de milho crioulo, diminuindo a dependência da agricultura em relação aos pacotes tecnológicos das empresas transnacionais do setor.

Pontualmente, foca-se a análise no sul do estado do Rio Grande do Sul, no município de Canguçu, um polo de agricultura familiar, onde se destaca o papel desenvolvido pela UNAIC, ao organizar a produção, comercialização e distribuição dos excedentes de sementes crioulas. Com isso, muitos produtores resistiram ao processo de modernização agrícola, marcado neste caso pelo domínio das chamadas "sementes híbridas" e continuam produzindo espécies crioulas de milho, feijão, entre 
outras variedades agrícolas. São produtores que buscam resgatar a importância das sementes crioulas e convertem-se, em muitos casos, em guardiões, retomando o modelo de agricultura praticada em períodos anteriores ao advento da Revolução Verde. Nesse contexto, é necessário enfocar o papel catalizador desenvolvido pela UNAIC ao unir os diferentes pontos da cadeia produtiva das sementes, extrapolando as barreiras físicas do município de Canguçu.

\section{O papel desenvolvido pela união das associações COMUNITÁRIAS DO INTERIOR DE CANGUÇU (UNAIC)}

A União das Associações Comunitárias do Interior de Canguçu (UNAIC) compreende um universo onde estão filiadas várias associações e grupos de agricultores familiares. Fundada em 18 de março de 1988, é uma instituição com 30 anos de atuação na defesa dos direitos dos agricultores familiares, na promoção do desenvolvimento rural sustentável baseado em ações de agroecologia, no apoio ao associativismo e ao cooperativismo. Segundo Pinheiro (2001, p. 338-339), "desde o final da década de 1980, a fundação de associações de produtores tornou-se um fenômeno generalizado no país, colocando inúmeras indagações para os estudiosos e participantes dos movimentos sociais no campo". A produção de sementes crioulas a partir de núcleos organizados pela associação começou a ser realizada em setembro de 1994, instigada pela assessoria técnica das entidades parceiras, como a Pastoral Rural da Igreja Católica e o Centro de Apoio e Promoção da Agroecologia (CAPA), entidade ligada à Igreja Evangélica de Confissão Luterana no Brasil (IECLB). O programa de produção de sementes crioulas desenvolvido pela UNAIC e agricultores familiares nesse período recebeu o apoio da Empresa Brasileira de Pesquisa Agropecuária (EMBRAPA), que contribuiu com o programa através da realização de troca de material genético entre a empresa e os agricultores.

No ano de 1997, foi criado o Banco Comunitário de Sementes, com o objetivo de promover a troca de cultivares entre os agricultores, a reprodução e a preservação dessas variedades. Em 1999, a produção de sementes crioulas de milho e feijão passou a ser um programa institucional da UNAIC. Para tanto, foi realizado o cadastro junto ao antigo Departamento de Produção Vegetal (DPV) do Governo do Estado do Rio Grande do Sul, que oficializa a UNAIC como produtora de sementes. Com isso, a associação começou a atender novos mercados de comercialização, dentre os quais se destacaram a comercialização via o programa Troca-Troca de Sementes do Governo do Estado do Rio Grande do Sul, que propiciou o acesso às sementes por parte de comunidades tradicionais como as indígenas e quilombolas, além de assentados da reforma agrária.

No ano de 2001, a UNAIC recebeu, através de um programa do Governo do Estado do Rio Grande do Sul, uma Unidade de Beneficiamento de Sementes (UBS), que foi a primeira da América Latina a processar grãos, e a primeira e única UBS na América Latina a ser administrada exclusivamente por agricultores familiares. A unidade foi inaugurada em agosto de 2002, na ocasião da realização da $1^{\text {a }}$ Feira Estadual de Sementes Crioulas e Tecnologias Populares, que tinha como um dos principais objetivos a divulgação do trabalho de preservação de sementes realizado em Canguçu, além de possibilitar trocas de experiências de produção de sementes crioulas de todo o estado. Além desses objetivos, a feira visava despertar na comunidade local a importância da preservação e conservação da biodiversidade. Para a continuidade da discussão, destaca-se a realidade das famílias produtoras de sementes crioulas e 
suas características principais, vivências como agricultores e núcleos de reprodução social. Na continuidade da discussão, trazem-se os dados coletados em campo a partir das entrevistas, a consequente realidade e as perspectivas das famílias envolvidas diretamente na produção de sementes crioulas.

\section{SEMENTES CRIOULAS NO MUNICÍPIO DE CANGUÇU/RS A PARTIR DA PESQUISA DE CAMPO}

Dada a necessidade de demonstrar quem são os produtores de sementes crioulas e suas famílias, apresentam-se alguns aspectos dos dados obtidos como resultado da pesquisa de campo. A tabela 1 apresenta os estratos e a faixa etária por sexo dos membros dos componentes das famílias de produtores de sementes crioulas do município de Canguçu.

Tabela 1 - Faixa etária por sexo dos membros das famílias dos produtores pesquisados

\begin{tabular}{l|c|c|c}
\hline \multicolumn{1}{c|}{ Faixa Etária } & $\begin{array}{c}\text { Número de } \\
\text { Pessoas }\end{array}$ & Masculino & Feminino \\
\hline $0-9$ anos & 1 & 1 & - \\
\hline $10-19$ anos & 8 & 5 & 3 \\
\hline $20-29$ anos & 12 & 7 & 5 \\
\hline $30-39$ anos & 10 & 5 & 5 \\
\hline $40-49$ anos & 6 & 2 & 4 \\
\hline $50-59$ anos & 6 & 3 & 3 \\
\hline $60-69$ anos & 15 & 9 & 6 \\
\hline 70 anos ou mais & 2 & 2 & - \\
\hline TOTAL & $\mathbf{6 0}$ & $\mathbf{3 4}$ & $\mathbf{2 6}$ \\
\hline
\end{tabular}

Fonte: Pesquisa de campo, 2017.

Observa-se, na tabela 1, que as famílias de produtores são um reflexo dos processos de envelhecimento e masculinização do campo, tão presentes nos estudos científicos realizados no Brasil a respeito dessa temática. Presencia-se, por exemplo, nesse espaço de análise restrito a 60 pessoas, a existência de um número reduzido de pessoas em cada residência. Fato visível é a concentração nos estratos de população adulta e idosa, com a diminuição do número de crianças por casal, e até mesmo a presença de casais sem filhos. Por tratar-se de universo restrito de pessoas, não podemos estender as avaliações e generalizá-las para o conjunto populacional, mas um dado é marcante. A maioria dos lares rurais do município de Canguçu conta com poucas crianças ou, em alguns casos, sequer as possui, o que reflete, por exemplo, na diminuição da demanda por escolas rurais e até mesmo em seu fechamento, com a consequente concentração nas chamadas escolas polo, localizadas em centros urbanos. Outro fato visível ao longo da realização das entrevistas pode ser percebido pela presença de casais com mais de 60 anos de idade, cujos filhos maiores moram nas áreas urbanas e retornam apenas nos finais de semana para a casa dos pais. 
A tabela 2 mostra a escolaridade dos membros das famílias dos produtores de sementes crioulas, ressaltando a formação destes e revelando as tendências em termos educacionais que se apresentam no universo rural.

\section{Tabela 2 - Escolaridade dos membros das famílias dos produtores pesquisados}

\begin{tabular}{l|c}
\hline \multicolumn{1}{c|}{ Escolaridade } & Número de Pessoas \\
\hline Ensino Fundamental Incompleto & 27 \\
\hline Ensino Fundamental Completo & 10 \\
\hline Ensino Médio Incompleto & 7 \\
\hline Ensino Médio Completo & 6 \\
\hline Ensino Superior Incompleto & 6 \\
\hline Ensino Superior Completo & 1 \\
\hline Analfabeto & 2 \\
\hline Não está em idade escolar & $\mathbf{6 0}$ \\
\hline TOTAL &
\end{tabular}

Fonte: Pesquisa de campo, 2017.

A maioria, ou seja, $45 \%$ dos membros das famílias de produtores possui o ensino fundamental incompleto, especialmente as pessoas com mais de 50 anos. Já os jovens, em sua maioria, concluíram o ensino fundamental $(16,6 \%)$, e muitos o ensino médio (10\%). Verifica-se, ainda que alguns jovens integrantes dessas famílias ingressaram no ensino superior, dos quais $1,6 \%$ concluíram e $10 \%$ concluirão nos próximos anos.

Já quando objetiva-se analisar a principal fonte de renda das 17 famílias produtoras de sementes crioulas pesquisadas, aparecem como fundamentais a aposentadoria rural, a produção de fumo e a renda mista. Ao entrevistarmos os produtores de sementes crioulas, verificamos que parte das famílias (oito do total) tem a aposentadoria como a principal fonte de renda da propriedade. Para duas famílias, a principal fonte de renda é a produção de fumo. No caso dos produtores que optamos por classificar como renda mista (sete), verifica-se a diversidade de fontes de renda, em que o agricultor não identifica claramente uma renda principal, mas, sim, diversas fontes. Nesse caso, existem famílias que produzem, além das sementes crioulas, leite, fumo e ainda podem contar com algum aposentado na família.

É importante destacar o papel representado pela aposentadoria rural na realidade estudada, pois em muitos casos é a principal fonte de renda das famílias, embora a complementem com outras atividades, como a criação de ovinos para obtenção da lã e carne, com a posterior comercialização dos excedentes. Mas é a aposentadoria que garante o sustento dessas famílias, e, como destaca o produtor entrevistado, "se não fosse a aposentadoria, não sei o que seria do agricultor. O trabalho na lavoura é duro, de sol a sol, e, com a velhice, se vai perdendo as forças". A fala do agricultor é pontual, uma vez que muitos aposentados encontraram nas sementes crioulas uma forma de garantir o cultivo de sementes que eram utilizadas por seus antepassados e complementar a renda. De um modo geral, as áreas utilizadas para o cultivo de sementes crioulas são de dimensões reduzidas e exigem menor esforço físico que as culturas tradicionais presentes na região investigada, como a produção de fumo.

Salienta-se que em todos os casos estudados, a produção de sementes crioulas é uma forma secundária de renda, sendo as formas principais a aposentadoria, 
produção de fumo, criação de animais (ovelhas, porcos, frangos, gansos, entre outros) para comercialização dos excedentes, ou até mesmo o consórcio de diferentes atividades (fumo, leite, sementes crioulas). No caso das propriedades familiares, é com os casais jovens que se verificam as possibilidades de ampliação das atividades de produção de sementes crioulas. É exemplo a entrevista realizada com o produtor da localidade da Solidez: "As sementes crioulas têm muitas possibilidades, só falta incentivo para que outros colonos usem as variedades crioulas. Se depender de mim e da minha família, temos disposição para aumentar a área plantada". Para ressaltar os dados coletados em campo, o quadro 1 apresenta os dezessete produtores pesquisados e suas respectivas variedades agrícolas produzidas.

\section{Quadro 1 - Variedades produzidas pelas famílias pesquisadas}

\begin{tabular}{|c|c|}
\hline Produtores & Variedades \\
\hline A & $\begin{array}{l}\text { Variedades de milho: Catete Branco, Amarelo, Oito Carreiros, } \\
\text { Farinha, Argentino Branco, Amarelo, Roxo, Caiano Roxo, Amarelo, } \\
\text { Cunha, Dente de Ouro, Pipoca, e Milho Palha. Variedades de feijão: } \\
\text { Manteiga, Laguno, Bico de Ouro, Pitanga, Feijão Sopa, Sopinha, } \\
\text { Moro, Mulatinho, Tupi Riscado, Corujinha, Carioca, Feijão de Porco. } \\
\text { Variedades de amendoim: Vermelho, Branco, arroz de sequeiro. } \\
\text { Variedades de porongo: Cuiá Paraguaia e Porongo de Salada. O } \\
\text { agricultor possuía outras variedades que não lembrou no momento } \\
\text { da entrevista. }\end{array}$ \\
\hline B & $\begin{array}{l}\text { Variedades de milho: Amarelão, Varietal e Branco. Variedades de } \\
\text { feijão: Expedito, Guapo Brilhante, Campeira e Carioquinha. }\end{array}$ \\
\hline $\mathrm{C}$ & Feijao: Branco, Preto. Milho Varietal, Mandioca. \\
\hline $\mathrm{D}$ & Milho: Índio Roxo, Amarelo, Branco e Criolão. \\
\hline $\mathrm{E}$ & Milho Varietal. Feijão: Preto, Guapo e Brilhante. \\
\hline $\mathrm{F}$ & Milho: Dentado e Branco. Feijão. \\
\hline G & Milho: Branco e Amarelo. \\
\hline $\mathrm{H}$ & Feijão. Milho. Abóbora. Batata Inglesa. Pipoca. \\
\hline $\mathrm{I}$ & Milho e Feijão. \\
\hline 了 & Milho: Argentino, Branco. \\
\hline $\mathrm{K}$ & Feijão: Preto, Branco. Milho: Argentino, Catete. \\
\hline $\mathrm{L}$ & Milho: Aegentino, Criolão, Varietal AL 30. \\
\hline M & $\begin{array}{l}\text { Feijão: Miúdo, De Porco, Branco, Vermelho, Tubiano, Gigante. Milho: } \\
\text { Argentino Duro. Melância. Abóbora. }\end{array}$ \\
\hline $\mathrm{N}$ & $\begin{array}{l}\text { Melancia: Casca Amarela, Vermelha. Abóbora de baraço. Feijão } \\
\text { Preto. }\end{array}$ \\
\hline 0 & Milho: Cunha, Catete. \\
\hline $\mathrm{P}$ & Milho: Varietal AL 30, Caiano, Rajado. \\
\hline $\mathrm{Q}$ & Milho: Argentino, Branco, Amarelo, Pampa, Intruso. \\
\hline
\end{tabular}

Fonte: Pesquisa de campo, 2017.

Os produtores de sementes crioulas do município de Canguçu contam com o apoio de instituições, como CAPA e UNAIC, que desenvolvem o papel de instrumentalizar e organizar a cadeia produtiva. Os produtores entrevistados menci- 
onam a importância da UNAIC, mediadora das políticas públicas e da valorização das sementes crioulas. Outro fato interessante tem a ver com a diversidade de variedades cultivadas, em especial de milho, que é uma cultura agrícola importante na região como componente da alimentação para os animais da propriedade. Como pode ser observado na figura 3, verifica-se a presença da variedade de "milho cunha", que, segundo os produtores, apresenta ótimos resultados para confecção de silagem e rações, e, na figura 4, os chamados "porongos", utilizados para ornamentação em Centros de Tradições Gaúchas (CTGs) e festas típicas gaúchas.

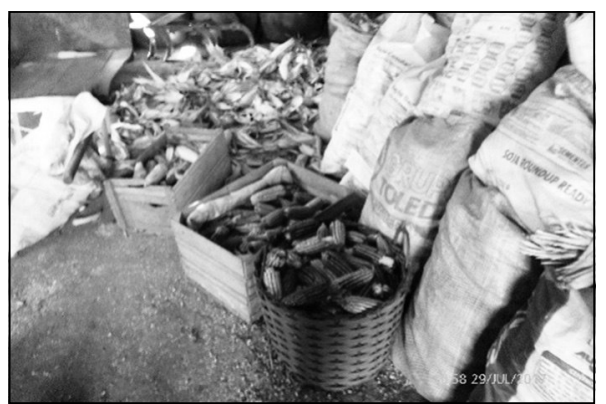

Figura 3 - Variedade de milho cunha

Fonte: Pesquisa de Campo, 2017.

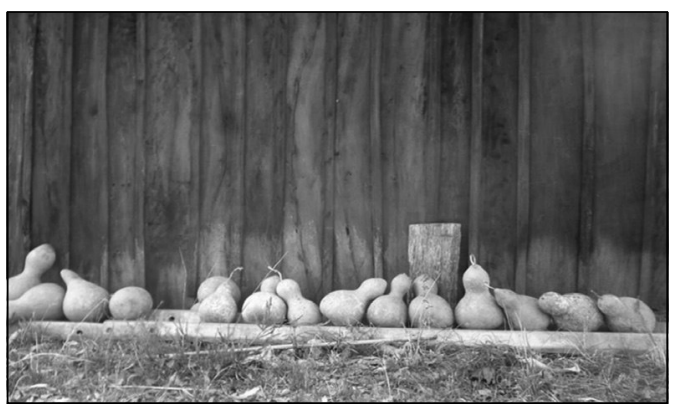

Figura 4 - Variedade porongos, secando ao sol

Fonte: Pesquisa de Campo, 2017.

Os dados de campo revelam particularidades destacadas pelos produtores, nesse caso da localidade do Remanso, 10 Distrito do município de Canguçu: "[...] se não fosse a cooperativa, não havia mais sementes crioulas na nossa região, as grandes sementeiras já teriam tomado conta de tudo". Os problemas inerentes às sementes crioulas estão presentes no âmbito da produção, comercialização e, principalmente, distribuição, com número limitado de produtores e falta de políticas institucionais com amplitude e maior aporte de recursos públicos. Como complementa o produtor entrevistado, na localidade de Passo do Lourenço, 40 distrito de Canguçu: "[...] nós, às vezes, via cooperativa vendemos alguma coisa para o Sindicato Rural, mas eles preferem pegar sementes das grandes empresas, no Troca-Troca de Sementes do governo do estado".

Por outra, vê-se que os agricultores destacam a relevância das sementes crioulas, como o produtor da localidade da Coxilha do Fogo, $3^{\circ}$ Distrito do município, coloca: "a semente crioula se adapta à terra mais fraca como nessa localidade, o meu pai sempre plantou milho-catete, já as variedades transgênicas, se não colocar uma enorme quantidade de veneno e adubo, não produz nada".

O cultivo das sementes crioulas transcende a simples relação comercial. São cultivos de saberes e tradições transmitidas de geração a geração. É importante destacar o material produzido pela Embrapa e o jornal A Vindima, onde se menciona que "a semente crioula tem uma estabilidade de produção pelo fato de ter se adaptado aos ambientes dos quais passou, além de todas as condições climáticas positivas e negativas. Mais do que isso, esses grãos carregam consigo um patrimônio cultural, com todo o trabalho e concepção do agricultor". Bevilacqua et al. (2014, p. 102) mencionam que "a conservação das sementes de variedades crioulas tornouse um aspecto fundamental na preservação da biodiversidade, principalmente no que concerne àquela de clima temperado no Brasil, visto que tem sido pouco visada pelas instituições de pesquisa e desenvolvimento". 
Entretanto, existem problemas ao longo da cadeia produtiva, como o exemplo apresentado pelo produtor, segundo o qual o Sindicato dos Trabalhadores Rurais de Canguçu (STRC) "opta" por distribuir sementes de milho, de grandes grupos empresariais e marcas "famosas". Esse fato decorre da falta de investimentos em políticas de financiamento e uso das sementes crioulas. Em razão disso, o agricultor fica submetido ao uso de variedades híbridas, que, além de não serem adequadas aos diferentes tipos de solo, são modificações genéticas feitas por grupos empresariais com atuação, em muitos casos, global. Como destaca o produtor da localidade de Lagoa do Junco, $1^{0}$ Distrito do município: "Nós, colonos, somos os verdadeiros resistentes e servimos de exemplo para a juventude. Tem muito agricultor que levou semente daqui, e hoje só utiliza as sementes crioulas para fazer a silagem, pela qualidade do milho, que é muito superior às variedades híbridas". Complementa o mesmo agricultor: "uma coisa importante para divulgar as sementes é a $8^{a}$ Feira Estadual, que acontecerá na semana que vem. Tem gente de vários locais, e inclusive a visita dos estudantes das escolas rurais serve para divulgar as sementes crioulas para a juventude, que serão o futuro do meio rural". Complementado as colocações do agricultor, a realização da $8^{a}$ Feira Estadual de Sementes Crioulas e Tecnologias Populares, realizada no mês de outubro de 2017, nos espaços internos e externos do Ginásio Municipal de Esportes de Canguçu, foi um dos momentos para a exibição das sementes crioulas e contou inclusive com a presença de pessoas dos países vizinhos. Como bem menciona o espaço digital de divulgação da referida da feira:

A Feira Estadual de Sementes Crioulas e Tecnologias Populares, é um evento de abrangência nacional com a participação e o intercâmbio de países da América Latina e MERCOSUL, como a Argentina, Chile, Venezuela, Uruguai e Paraguai. A Feira de Sementes, busca através de uma programação diversificada (seminários, oficinas, palestras, shows, etc.) enfocada na realidade dos agricultores, promover a informação e a formação destes agricultores quanto à importância da conservação da biodiversidade, sobretudo, a preservação das sementes crioulas e a sustentabilidade na agricultura familiar. (ESPAÇO DE DIVULGAÇÃO DIGITAL, 2017).

A produção de sementes crioulas no município revela-se como uma forma de afirmação da agricultura familiar e da resistência ao domínio dos grupos econômicos, especialmente das sementeiras. A posse das sementes crioulas confere autonomia a essas famílias e a liberdade de não estarem vinculadas aos pacotes tecnológicos fechados, além de dominarem uma tecnologia soberana que é a produção de sementes. A atuação da cooperativa UNAIC e a realização da Feira Estadual que acontece no município de Canguçu (bi)anualmente propiciam a disseminação dessas tecnologias populares e solidárias, por meio das quais os agricultores têm acesso a sementes adequadas à realidade local, e suas propriedades constituem-se a posteriori em polos de difusão dessas alternativas. Os agricultores entrevistados, por suas histórias de luta e persistência, são o exemplo claro das possibilidades de autonomia e da existência de uma realidade no meio rural, pontuada pelo respeito ao meio ambiente e perspectivas de futuro.

\section{CONSIDERAÇÕES FINAIS}

Neste artigo, buscou-se demonstrar a realidade da produção, comercialização e distribuição de sementes crioulas no município de Canguçu e o papel desenvolvido pela UNAIC, ao articular a cadeia produtiva das sementes. Percebe-se a relevância 
que a produção de sementes crioulas tem ao romper o ciclo de domínio das grandes empresas sementeiras. A iniciativa da UNAIC é pioneira no estado do Rio Grande do Sul, podendo servir de inspiração na retomada de uma produção soberana.

A realização da $8^{a}$ Feira Estadual de Sementes Crioulas e Tecnologias Populares foi um momento relevante para divulgar a importância da atividade em âmbito municipal, estadual, nacional e internacional, ao articular e integrar produtores e o público em geral. Possibilitou não só a exposição das inúmeras variedades de sementes crioulas disponíveis, bem como a realização de discussões com enfoque na agricultura familiar e no intercâmbio de ideias sobre diferentes concepções que norteiam a complexidade do mundo agrário.

A produção de sementes crioulas na realidade pesquisada compreende uma forma secundária de renda, indispensável para os produtores e suas famílias, pois, ao produzirem a própria semente, tornam-se autônomos perante as grandes empresas sementeiras. Além disso, permitem produzir alimentos para o uso doméstico, para o sustento da família, criação de animais e também para a comercialização do excedente.

As sementes crioulas, por sua vez, garantem a possibilidade de menores impactos ambientais, quando comparadas com a existência de variedades híbridas, como ficou demonstrado nas entrevistas com os agricultores. As variedades crioulas têm melhor adaptação a solos considerados pobres do ponto de vista pedológico, garantindo assim, o equilíbrio ambiental na prática agrícola.

\section{REFERÊNCIAS}

ALMEIDA, M. W. B. Narrativas agrárias e a morte do campesinato. RURIS, Campinas/ SP, v. 1, no. 2, p. 157-186, 2007.

ALVES MAZZOTI, A. J; GEWANDSZNAJDER, F. O método nas ciências naturais e sociais: pesquisa quantitativa e qualitativa. São Paulo: Pioneira, 1999.

AMORIM, L. O. et al. O movimento dos pequenos agricultores e a luta em defesa das sementes crioulas no Alto Sertão Sergipano, Brasil. Revista de Geografia (Recife), v.34, n. 1, p. 71-90, 2017. Disponível em: <https://ainfo.cnptia.embrapa.br/digital/ bitstream/item/160624/1/1303-4332-1-PB.pdf. >. Acesso em: 22 de dez. 2017.

AQUINI, D. M. Guardiões de sementes do sul do RS e a construção de um sistema intersocial. 2015. 120f. Dissertação (Programa de Pós-Graduação em Sociologia) - Universidade Federal de Pelotas, Pelotas, 08 de Setembro de 2015.

ARBoledA, B. H. L. Práticas de armazenamento de sementes do Povo Ticuna na tríplice fronteira amazônica (Brasil- Colômbia- Peru). Espaço Ameríndio, Porto Alegre, v. 10, n. 2, p. 66-95, jul/dez. 2016. Disponível em: <http://seer.ufrgs.br/index.php/ EspacoAmerindio/article/view/63836/39762.> Acesso em: 22 dez. 2017.

BEVILACQUA, G. A. P. et.al. Agricultores guardiões de sementes e a manutenção da agrobiodiversidade. Cadernos de Ciência \& Tecnologia, Brasília, v. 31, n. 1, p. 99-118, jan./abr, 2014. Disponível em:<https://seer.sct.embrapa.br/index.php/cct/ article/view/19445/12516>. Acesso em: 24 dez. 2017.

BRASIL. Decreto No 1946, de 28 de junho de 1996. Cria o Programa Nacional de Fortalecimento da Agricultura Familiar - PRONAF, e dá outras providências. Disponível em: <http://www.planalto.gov.br >. Acesso em: 09 Fev. 2018. 
BRASIL. Lei No 10.711, de 05 de agosto de 2003. Dispõe sobre o Sistema Nacional de Sementes e Mudas e dá outras providências. Disponível em: <http:// www.camara.gov.br/>. Acesso em: 16 Ago. 2017.

BRASIL. Lei No 11.326, de 24 de julho de 2006. Estabelece as diretrizes para a formulação da Política Nacional da Agricultura Familiar e Empreendimentos Familiares Rurais. Disponível em: <<http://www.planalto.gov.br >>. Acesso em: 09 Fev. 2018. DESLAURIERS, J. P; KÉRISIT, M. O delineamento da pesquisa qualitativa. In: POUPART, J. A pesquisa qualitativa: enfoques epistemológicos. Petrópolis: Vozes, 2008. Parte II, p. $127-153$.

DUVAL, H. C; FERRANTE, V. L. S. B; BERGAMASCO, S.M. P. P. Sobre o uso da teoria do campesinato na contemporaneidade. Raízes, Campina Grande/PB, v. 35, p. 62-78, 2015. Disponível em: < http://revistas.ufcg.edu.br/raizes/artigos/Artigo_353.pdf>. Acesso em: 05 Abr. 2018.

FEIRA ESTADUAL DE SEMENTES CRIOULAS E TECNOLOGIAS POPULARES. A Feira. Disponível em: <http://www.feiradassementes.com.br>. Acesso em: 03 Mar. 2018.

GERHARDT, T. E; SILVEIRA, D. T (Orgs). Métodos de Pesquisa. Coordenado pela Universidade Federal do Rio Grande do Sul (UFRGS), Universidade Aberta do Brasil (UAB) e pelo Curso de Graduação Tecnológica - Planejamento e Gestão para o Desenvolvimento Rural. Porto Alegre: Editora: UFRGS, 2009, p. 1-114. Disponível em: <http://www.ufrgs.br/cursopgdr/downloadsSerie/derad005.pdf>. Acesso em: 09 jan. 2017.

GRÍGOLO, S.C. A renovação das estrategias de lutas na agricultura: o caso das festas de sementes crioulas no sul do Brasil. 2016. 294 f. Tese (Programa de PósGraduação em Extensão Rural) Universidade Federal de Santa Maria, Santa Maria, 30 de Agosto de 2016.

INSTITUTO BRASILEIRO DE GEOGRAFIA E ESTATÍSTICA (IBGE). Censo Agropecuário 2006. Rio de Janeiro: 2006. Disponível em: <http://www.ibge.gov.br>. Acesso em: 18 ago. 2017.

Censo Demográfico 2010. Rio de Janeiro: 2010. Disponível em: <http:// www.ibge.gov.br>. Acesso em: 19 ago. 2017.

JORNAL A VINDIMA (O Jornal da Vitivinicultura e da Agricultura familiar). Sementes Crioulas: Produzem e preservam as espécies. Disponível em: <http:// www.avindima.com.br/?p=8646>. Acesso em: 24 dez. 2017.

NEVES, D. P. A agricultura familiar e o claudicante quadro institucional. In: LOPES, E. S. A; MOTA, D.M; SILVA, T. E.M (Orgs.). Ensaios: desenvolvimento rural e transformações na agricultura. Aracaju: Embrapa Tabuleiros Costeiros, 2002, p. 133159.

OLIVEIRA, A. U. A longa marcha do campesinato brasileiro: movimentos sociais, conflitos e Reforma Agraria. Estudos Avançados, São Paulo, v. 15, n.43, p. 185206, 2001. Disponível em: http://www.scielo.br/ scielo.php?script=sci_arttext\&pid=S0103-40142001000300015. Acesso em: 05 Abr. 2018.

ORLANDINI, T. T. A importância das sementes crioulas na agricultura familiar. Portal: Região dos Vales, 2017. Disponível em: <http://www.regiaodosvales.com.br>. Acesso em: 18 ago. 2017.

PAULINO, J. S; GOMES, R. A. Sementes da Paixão: agroecologia e resgate da tradição. Revista de Economia e Sociologia Rural, Piracicaba-SP, v. 53, n.3, p. 517-528, Jul/Set, 2015 - Impressa em Nov. 2015. 
PINHEIRO, D. A agricultura Familiar e suas organizações: o caso das associações de produtores. In: TEDESCO, J. C ((Org.)). Agricultura Familiar: realidades e perspectivas - 3a edição. Passo Fundo: UPF, 2001, cap. 9, p. 337-365.

RICHARDSON, R.J. Et al. Pesquisa Social: Métodos e técnicas. $2^{\circ}$ ed. São Paulo: Atlas, 1989.

SEYFERTH, G. Campesinato e o Estado no Brasil. Mana (UFRJ), v. 17, p. 395-417, 2011. Disponível em: < http://www.scielo.br/scielo.php?script=sci_arttext\&pid=S010493132011000200006>. Acesso em: 2 Fev. 2018.

UNIÃO DAS ASSOCIAÇÕES COMUNITÁRIAS DO INTERIOR DE CANGUÇU. (UNAIC). Sementes Crioulas. Disponível em: <http://www.unaic.blogspot.com.br>. Acesso em: 18 Ago. 2017.

WANDERLEY, M. N. B. Raízes Históricas do Campesinato Brasileiro. ANAIS DO XX ENCONTRO ANUAL DA ANPOCS, Caxambu, 1996. p. 1-18.

Agricultura Familiar e Campesinato: rupturas e continuidade. Estudos Sociedade e Agricultura, Rio de Janeiro, v. 21, p. 42-61, 2004. Disponível em: <https://wp.ufpel.edu.br/leaa/files/2014/06/Texto-6.pdf>. Acesso em: 2 Abr. 2018.

- Mundo Rural como Espaço de vida: reflexões sobre a propriedade da terra, agricultura familiar e ruralidade. Porto Alegre: Ed. da UFRGS, 2009.

. O campesinato brasileiro: uma história de resistência. Revista de Economia e Sociologia Rural (impresso), Brasília, v. 52, p. 25-44, 2014.

Recebido em maio de 2018

Aceito em outubro de 2018 